\title{
Ethical practice in the nursing profession: A normative analysis
}

\author{
J M Mathibe-Neke, BA Cur, BA Cur (Hons) (Nursing Education and Community Health), MMed (Bioethics Health Law), MSc Nursing Science, \\ PhD, Dip Midwifery, Dip General Nursing
}

Department of Health Studies, School of Humanities, University of South Africa, Pretoria, South Africa

Corresponding author: J M Mathibe-Neke (mathijm@unisa.ac.za)

\begin{abstract}
Background. In response to an increasing amount of litigation relating to nursing care errors, negligence or acts and omissions that arise mostly due to unprofessional or unethical behaviour, compounded by the growing awareness of patients' rights, nurse practitioners need an intervention by the regulatory body, the South African Nursing Council (SANC).

Objective. The argument presented pertains to the obligatory role of the SANC as a regulatory body to uphold professional and ethical practice for nurses in terms of the nursing curriculum, the scope of practice, the code of ethics and continuing professional development. Methods. The methodology was based on the analysis of relevant SANC legislation under the provision of the Nursing Act No. 33 of 2005, as amended. Document review, a technique used to 'categorise, investigate, interpret and identify limitations of written documents' was undertaken. The study references some of the general literature relating to nursing ethics and professionalism.

Results. Because the SANC is the custodian of the nursing profession that provides oversight over nursing practice and nursing education, the council needs to accelerate the execution of its role following numerous concerns presented during pre-summit provincial consultations and at a summit in 2011 about its ability to provide the necessary services, which include upholding professional and ethical practice.

Conclusion. The overall impact of the analysis lies in its contribution to enhancing nursing practice, with a specific focus on upholding professional and ethical practice. SANC as a custodian of the nursing profession needs to address limitations and develop a balance for the regulation and monitoring of ethical practice in both nursing education and clinical practice.
\end{abstract}

S Afr J Bioethics Law 2020;13(1):52-56. https://doi.org/10.7196/SAJBL.2020.v13i1.690

South Africa $(S A)$ is the first country in the world to achieve state registration for nurses, through the establishment of the SA Nursing Council (SANC) in 1944, which served as a significant milestone in the governance and the regulation of the nursing profession. ${ }^{[1]}$

Nurses and midwives are expected to comply with SANC policies and legislation governing their profession, to enable them to assess the health needs of the community and intervene accordingly. ${ }^{[2]}$ Nursing practice is grounded in standards, ethical values and professional regulation, which is essential for competency in ethical clinical decision-making. ${ }^{[3]}$

As stated by the International Council of Nurses $(\mathrm{ICN}){ }_{{ }^{[4]}}^{[3}$ nurse practitioners need more than just an understanding of ethics for ethical decision-making; they also require the ability to display commitment to ethics through appropriate ethical behaviour. It seems sensible that if an ethically acceptable level of nursing care is to be achieved, a critical reflection is required on the SANC as the regulatory body for the nursing profession, to ensure that moral obligations for nursing practice are imposed.

The experiences that women describe in a report ${ }^{[5]}$ in monitoring maternal care in the Eastern Cape Province of SA contribute to a violation of human rights, as evidenced by the cruel, inhuman and degrading treatment received by pregnant women. This kind of behaviour from midwives as nurse practitioners is humiliating for patients and is unethical.
The Minister of Health ${ }^{[6]}$ announced the lawsuits already settled by the various provincial departments of health in SA as amounting to ZAR1.7 billion in the past 7 years. It has been reported that nurse practitioners often raise issues of shortage of staff and adverse working conditions as mitigating factors when defending themselves against complaints of failure to continuously assess, monitor and evaluate the wellbeing of patients..$^{[6]}$ Selebi and Minaar ${ }^{[7]}$ revealed a high dissatisfaction of nurses in public hospitals that may impact on quality care. The authors suggested human resource strategies that will retain nurses in their posts with the aim of enhancing quality patient care. Nyathi and Jooste ${ }^{[8]}$ corroborate these findings, explaining that increased workload leads to low morale, which may lead to low standards of care, and that any practice falling below the required standard of professionalism constitutes malpractice.

Arries ${ }^{[9]}$ conducted a study that led to the formulation of practice standards in ethical decision-making, based on the SANC's disciplinary reports on cases of unprofessional conduct. Disciplinary cases reflected scenarios where a nurse had made decisions to not maintain, restore or promote the health of a patient that were probably unprofessional. The study further concluded that the nurse's clinical decision-making was 'ineffective, as it did not adhere to the framework of clinical, ethical and legal correctness for any nursing action and ethical decision-making'.

Mawela ${ }^{[10]}$ states that it is imperative for those carrying the responsibility of teaching nurses at colleges and universities to 
address this shortcoming in ethical practice if the profession is to be sustained as a noble one. Professional governance is vital in protecting and ensuring quality nursing education through relevant legislation. Within the standards of professional nursing practice are contained the responsibilities that nurse practitioners are accountable for, and their professional values and priorities. As highlighted by Catallo et $a l,{ }^{[11]}$ it is crucial that professional bodies engage nurses in health and nursing policy development as stakeholders. This will strengthen adherence to policies or rules and regulations as determined by regulatory bodies.

The research questions addressed in this study are three-fold:

- Is the SANC, as the regulatory body for nurses in SA, morally obliged to uphold and maintain professional and ethical conduct that is morally appropriate for the nursing profession?

- Are there shortcomings in terms of the role of the SANC in enhancing professional and ethical practice for nurses?

- What should nurse practitioners refer to, in order to develop moral wisdom and to establish a more complete understanding of moral nursing practice, other than virtue ethics?

\section{The role of SANC as a regulatory body}

Nursing councils as regulatory bodies are mandated by government statute to regulate the education and practice of the nursing profession. ${ }^{[12,13]}$ A regulatory body might also act as a membership organisation that often restricts the right to practise if a nurse is not a fully paid-up member, as is the case with the SANC.

As stated by Hoskins et al., ${ }^{[13]}$ there is little consensus on the importance of ethics education in nursing, the role of ethics education in nursing curricula and outcomes that can be achieved from ethics education. The purpose of the Hoskins et al. study was to highlight the importance of ethics in nursing education and the research and clinical opportunities that support its inclusion, and to address ways to incorporate ethics inquiry in nursing curricula for educating future generations of nurses. As a recommendation, the findings of the study suggest collaboration and partnership with regulatory bodies such as the SANC, as stakeholders, to standardise ethics content in academia.

Regulatory bodies play a significant role in ensuring the quality of nursing education, which is education that contributes fully to the development of the individual and of society, characterised by a degree of commitment towards excellence, and the inculcation of human values in the students. ${ }^{[13]}$ This role can be achieved by, among other means, regulatory bodies playing the role of facilitators, the establishment and maintenance of education standards, quality assurance, continuous professional development (CPD) and the revision of curricula to make them more relevant to current healthcare needs.

McCarthy et al. ${ }^{[14]}$ conducted a survey in Nairobi to establish stakeholders' roles, responsibilities and involvement in nursing and midwifery regulation, and the challenges regarding the regulation of the nursing profession. The stakeholders represented 13 African countries, with equal representation among chief nursing officers, professional association presidents and academicians.

The survey revealed that all stakeholders were involved in activities pertaining to the professional development of nurses and midwives, while only $78 \%$ of academicians stated that they were represented on the national council. The challenges in nursing regulation that were identified included: lack of capacity of nursing councils to carry out their regulatory functions; lack of autonomy; insufficient human resources and expertise in council members; lack of monitoring of professional conduct and the lack of the regulation of nursing education, which was the second-most frequently cited challenge. ${ }^{[14]}$

\section{Problem statement}

There is a general concern among communities regarding moral degeneration in the nursing profession, as reflected in the media and acknowledged by the SANC in the October 2019 volume 10 newsletter, ${ }^{[15]}$ and as raised by the then-Minister of Health during a national nursing summit that was held during April 2011 in Gauteng Province. The overall aim of the summit was to 'reconstruct and revitalise the nursing profession' by addressing the challenges faced by the profession at large. ${ }^{[6]}$ Professional ethos and ethics was one of seven themes that emerged from the deliberations. A national core curriculum in which ethics content would be incorporated into all basic and post-basic nursing programmes was recommended at this summit, as a foundation for ethical practice.

The argument presented in the present article is that the SANC has a moral obligation to ensure that nurse practitioners are encouraged and empowered in becoming ethical professionals.

The above claim is defended by the following arguments: the curriculum content as the foundation of nursing education should address ethical and legal aspects of nursing adequately; the scope of practice for nurse practitioners should reflect ethical practice; and the code of ethics for nursing practitioners in SA, as developed by SANC in $2013^{[16]}$ is, on its own, not adequate to equip nurses with ethical principles, moral norms and legal perspectives related to healthcare. The objectives of the SANC, as stated in the Regulations Regarding the Scope of Practice of Nurses and Midwives ${ }^{[17]}$ are broadly stated as being to 'uphold and maintain professional and ethical standards for nursing', and need to be further unpacked.

Ethics content in the ethos and professional practice of nursing is, to a certain extent, included in nursing curricula. However, it has been noted that educators have largely not succeeded in unpacking ethics content in teaching, as stated by London and Baldwin-Ragaven. ${ }^{[18]}$ Based on the Minister of Health's concern ${ }^{[6]}$ regarding declining ethical practice by nurse practitioners, and the general complaints from healthcare users, one can make an assumption that nurses do not seem to regard ethics as significant to their professional role and practice.

\section{Study objectives}

The objectives of the present article are to:

- provide a normative account of the obligations of the SANC in promoting ethical practice in the nursing profession

- defend the fundamental claim that the SANC has a legal and moral obligation to promote ethical practice in the nursing profession

- identify - on the basis of international best practice and professional ethical principles - some of the strategies the SANC ought to adopt in order to fulfil its obligation to promote ethical practice in the nursing profession.

Ethical clearance was obtained from the Human Research Ethics Committee of the University of the Witwatersrand (ref. no. W-CJ140905-1). The researcher ensured the relevance of the documents 
reviewed to the research problem and purpose, and ascertained that the 'content of the documents fits the conceptual framework of the study'. Authenticity, credibility, accuracy, representativeness and meaning ${ }^{[19]}$ were addressed through confirming the endorsement of documents by relevant organisations. The researcher further demonstrated objectivity and sensitivity in the selection and analysis of data from reviewed documents. ${ }^{[2]}$

\section{Methods}

This report is purely normative in nature. However, the typical research methods and standards applicable to philosophical research were applied. The study primarily involved the interpretation and critical analysis of salient texts, and the posing and defence of new arguments. A critical analysis of relevant texts involved the definition and clarification of concepts, the identification and criticism of assumptions, the analysis and evaluation of theoretical frameworks, the development and defence of arguments, the use of counterexamples and the articulation of the most plausible interpretation of significant concepts found in the sources.

An analysis of relevant SANC legislation under the provision of the Nursing Act No. 33 of 2005, ${ }^{[17]}$ as amended, was conducted.

Document review, a technique used to 'categorise, investigate, interpret and identify limitations of written documents and implementations', as discussed by Payne and Payne, ${ }^{[21]}$ was applied in the context of this study. The analysis of documents is based on the positivist perspective that reality is universal, objective and quantifiable. ${ }^{[22]}$ The study references some of the general literature relating to nursing ethics and professionalism.

\section{Argumentative strategy}

The researcher argues that the SANC is morally obliged to uphold and maintain professional and ethical practice for the nursing profession, with reference to the nursing curriculum and the scope of practice for nurses, and that it is crucial for nurse practitioners to possess knowledge of ethics, and to apply ethical and legal standards when making decisions in clinical practice, and as such contribute to the growth of bioethics, and function effectively as moral agents in the healthcare system.

The researcher's argument also reflects on the obligation-based moral theories of utilitarianism and deontology, regarding some of their well-known flaws and their possible impact on the nursing profession. Utilitarianism revolves around the concept of 'the end justifies the means,' a normative system that provides standards by which an individual nurse ought to act so as to produce the best consequences possible in nursing care. From the deontological perspective, the SANC is duty-bound as a regulatory body to provide directives and maintain ethical nursing practice, based on Kant's hypothetical imperative and the duties or rules that nurse practitioners have to observe if the outcome of ethical healthcare is to be met. The above claim is defended by the following arguments: the curriculum content as the foundation of nursing education should address ethical and legal aspects of nursing adequately; the scope of practice for nurse practitioners should reflect ethical practice; and the code of ethics for nursing practitioners in SA, as developed by SANC in 2013, is on its own not adequate to equip nurses with ethical principles, moral norms and legal perspectives related to healthcare. The most important premise of the present argument is that in order to address ethical behaviour among nurses, the teaching of ethics for nurses should begin theoretically, in the classroom, and not only in a form of code of ethics.

Furthermore, as a profession, nursing undertakes a specific ethical commitment to maximise the wellbeing of those under nursing care with reference to, for example, the Nurses' Pledge of Service and the social contract. The implication is that nurse practitioners should advocate for the promotion of the rights of and uphold the ethical care of those seeking healthcare, with reference to the Bill of Rights as stipulated in the Constitution. ${ }^{[23]}$

\section{Discussion}

\section{Is the SANC, as the regulatory body for nurses in SA, morally obliged to uphold and maintain professional and ethical conduct that is morally appropriate for the nursing profession?}

The SANC was established by section 2 of the Nursing Act, as amended, and continues to exist as a juristic organisation. SANC is the regulating body responsible for setting standards of practice and education for nurse practitioners in $\mathrm{SA}$, with its mission statement being 'to serve and protect healthcare users by regulating the nursing profession' ${ }^{[24,25]}$

The SANC is, as such, morally and legally obliged to ensure and maintain ethical conduct, as one of its stipulated functions mandated by the government. The SANC's legal obligation is with reference to the Constitution, ${ }^{[23]}$ which declares the right to healthcare for all citizens, the National Health Act No. 61 of 2003 that states a healthcare practitioner's obligation to care, and the Nursing Act, the objectives of which are to uphold and maintain professional and ethical standards within nursing. With reference to the Nursing Act, SANC is mandated by the government to regulate the nursing profession in the interest of the public.

Nursing regulatory bodies have a responsibility to develop standards that address the needs of the public, via educational programmes, policies, procedures, protocols and the evaluation of nursing service delivery systems. ${ }^{[2]}$ Standards describe competencies in clinical nursing practice that relate to the quality of nursing education undertaken. ${ }^{[11]}$

\section{Are there shortcomings in terms of the role of the SANC in enhancing professional and ethical practice for nurses?}

SANC seems to have focused for a long period on registration, setting standards of licence to practise as a nurse and the commissioning of disciplinary activities, with less focus on addressing critical professional competencies concerning ethical practice. It is only post the national summit of 2011 that measures have been put in place to address ethical practice, for example, the development of the code of ethics for nurse practitioners by SANC, ${ }^{[16]}$ and initiating CPD programmes, as reflected in SANC circular 3/2018 and as stipulated in the CPD framework ${ }^{[27]}$ for nurses and midwives/accoucheurs. The SANC demonstrated responsibility by developing the code of ethics in 2013; however, there are inherent challenges in teaching these principles or concepts as part of nursing education.

Further interventions by SANC are, for example, the launching of a marketing campaign during October 2019, \#bethatnurse, ${ }^{[15]}$ that aims to enhance professionalism in nursing. The SANC 15th 
Council Achievement report (unpublished) of a workshop hosted for stakeholders from 18 to 19 June 2018 in Johannesburg reflects one of the 11 focus areas discussed, 'Are ethical and professional values still relevant for nursing in the future?' This is a very concerning question to ask. It would be interesting to find out what transpired regarding this statement, but unfortunately, I could not access a follow-up report.

The most significant shortcoming is a limitation of the ethical content that reflects in the SANC curriculum, as the nursing curriculum should form a foundation for nursing ethos and professional practice.

\section{What should nurse practitioners refer to, to develop moral wisdom and to establish a more complete account of moral nursing practice, other than virtue ethics?}

'The ethics of care [...] turns out to be one part of the ethics of virtue, ${ }^{\prime[29]}$ which implies that virtues alone cannot enable a nurse to provide care that is ethically based. The ethics of virtue is characterbased, an internal part of one's identity, and is achieved through the socialisation and continuing refinement of the morality of a nurse who elects to follow a role model who represents the hidden curriculum. As stated by Er and Sehiralti, ${ }^{[28]}$ 'appropriate ethical training methods and good role models can help students acquire attributes that are important for the nursing profession and combine them with the attributes they already have.' Much as caring is viewed from a practical perspective, it is crucial that the nurse is equipped with cognitive, affective and psychomotor skills, which applies to intellectual virtue, as described by Aristotle, as both moral and intellectual virtues, which are incorporated in caring. The cognitive, affective and psychomotor domains of learning are, as such, important to sustaining a caring ethic, which address the principle of knowing what to do, when and how in a caring process. ${ }^{[29]}$

Nurse practitioners have a clear obligation to respect the dignity of service users. The notion of respecting the dignity of human beings is at the heart of ethical codes, as stated by Amnesty International and in the Constitution of SA. ${ }^{[23]}$ The International Council of Nurses ${ }^{[4]}$ has supported the above by stating that the nurse should demonstrate professional values such as respectfulness, responsiveness, compassion, trustworthiness and integrity', and furthermore, that a nurse 'should strive to foster and maintain a practice culture promoting ethical behaviour, and contribute to an ethical organisational environment'.

The literature indicates global challenges regarding caring for healthcare users in an ethically acceptable manner by nurse practitioners, emanating from various factors that include a lack of both material and human resources. ${ }^{[30]}$ For nurse practitioners to overcome this situation, the SANC must come on board as the regulatory body. The facilitation of ethics education in nursing students is core, and fundamental to ethical practice. This statement is supported by Bagnasco et al. ${ }^{[31]}$ in their argument that 'nurses do not always have the competences to engage in ethical practice, and ... ethics education can increase ethical perception in nursing students and develop their reflective skills in a safe learning environment.' The authors further recommend that 'clinical training should offer students a learning opportunity that goes beyond the identification of psychological needs, symptoms and nursing interventions [but also includes] the identification of the values, choices and rights of the person they care for ${ }^{\prime[3]]} \mathrm{A}$ call for an increased awareness of social conscience in all health professionals in support of ethical practice has been made by Antwi et al. ${ }^{[32]}$

\section{Strategies recommended for the SANC}

It is therefore recommended that the SANC:

- reflects on service delivery and challenges as a basis to transform nursing regulation

- reflects on South African Qualification Authority-level descriptors for ethics and professional practice as a basis to develop a nursing curriculum that will provide nurses with a theoretical foundation for ethical behaviour, which was also recommended at the national summit of 2011 (recommendation 3.3 $3^{[6]}$ ) - that ethics should be mainstreamed in nursing education and training

- foster relations (collaborate) with other relevant international organisations for an exchange of professional knowledge that contributes to the development of ethical standards and as such, better protects the health and welfare of healthcare users

- ensure a nurse's workplace environment that is conducive to ethical practice, which will result in improved patient outcomes - a conducive environment is characterised by supportive leadership, and the involvement of nursing staff in decision-making regarding the institution, i.e. participatory management, commitment to clinical practice, autonomy and accountability

- engage nurses as stakeholders in policy-making, specifically in matters relating to ethical practice

- support interdisciplinary ethics education programmes and research initiatives by developing ongoing collaboration with physicians and other healthcare professionals.

This is in line with strategy 5 for nursing education, ${ }^{[6]}$ by creating a positive practice environment 'that strengthen[s] and support[s] the workforce that will lead to a positive impact on patient outcomes and organisational cost-effectiveness that will ensure quality healthcare'.

The SANC, as a stakeholder in nursing practice, must advocate for and protect nurses regarding matters pertaining to ethical practice, rather than merely undertaking disciplinary procedures, and should, as such, foster the autonomy of the nurse practitioners as employees.

Addressing the power imbalance from the nursing perspective in relation to workload has an impact on delegation. There is an indication of horizontal violence in the nursing fraternity, which refers to the oppression of nurses by nurses. A power imbalance may lead to an increased likelihood of diminished patient care outcomes, limited autonomy and work dissatisfaction. This aspect can be addressed by use of strategies to review workloads, ${ }^{[3]]}$ in collaboration with the Chief Nursing Officer's Advisory Board.

Clinical supervision, setting standards for ethical practice in the workplace and 'tracking performance over time to determine the link between implementing improvement initiatives and achieving intended results ${ }^{[6]}$ will assist nurses to manage ethical dilemmas, which can be facilitated through the setting up of workplace ethics committees for clinical practice that will conduct review programmes that investigate and act upon complaints about nurses' practice before litigation occurs.

This should also be achieved by re-orientating nurse educators on the importance of ethics and professional practice in the context of nursing education, by including professional practice and work 
ethics as compulsory components of in-service education and CPD programmes for all categories of nurse practitioners, providing specific CPD points for ethical practice to enhance ethical behaviour and providing a framework for nurses to justify the ways in which nurse practitioners have maintained their competence and enhanced their practice that will allow them to renew their registration (the Canadian system).

Regulating entry into the nursing profession through eligibility criteria is necessary in order to curb the challenge of the nursing profession being a last resort in people's career choices. ${ }^{[11]}$

\section{Conclusion}

Armstrong, ${ }^{[33]}$ in a publication advocating a strong virtue ethic for nursing practice, claims that 'nurses are left without the necessary tools or a non-conducive environment to resolve moral conflicts.' The SANC needs to address the limitations and develop a balance for the regulation and monitoring of ethical practice in both nursing education and clinical practice, with the support of existing ethicolegal frameworks. However, ethical behaviour within nursing practice should not be imposed, but be context-realistic by considering its 'practical feasibility and its psychological acceptability'. ${ }^{[34]}$

The Scope of Nursing Practice, the Standards of Professional Nursing Practice and the Code of Ethics for Nurses should serve as standards and points of reference for legislation and regulatory policies to assure protection of the public's safety. ${ }^{[26]}$

Acknowledgements. The University of South Africa (UNISA) for financial support. Prof. Kevin Behrens and Dr Jillian Gardner for supervising the project.

Author contributions. Sole author.

Funding. UNISA.

Conflicts of interest. None.

1. Kotzé WJ. The South African Nursing Council. Curationis 1985;8(4):1-14. https:// doi.org/10.4102/curationis.v8i4.627

2. Maputle SM, Hiss DC. Midwives' experiences of managing women in labour in the Limpopo Province of South Africa. Curationis 2010;33(3):5-14. https://doi. org/10.4102/curationis.v33i3.2.2

3. South African Nursing Council. The relationship between the scopes of practice, practice standards and competencies. Pretoria: SANC, undated.

4. International Council of Nurses. The ICN Code of Ethics for Nurses. Geneva: ICN, 2012

5. Human Rights Watch. Stop making excuses. Accountability for maternal health care in South Africa. New York: HRW, 2011.

6. National Department of Health, South Africa. The national strategic plan for nurse education, training and practice 2012/13 - 2016/17. Pretoria: NDoH, 2011.

7. Selebi C, Minnaar A. Job satisfaction among nurses in a public hospital in Gauteng Curationis 2007;30(3):53-61. https://doi.org/10.4102/curationis.v30i3.1102

8. Nyathi $\mathrm{M}$, Jooste K. Working conditions that contribute to absenteeism among nurses in a provincial hospital in the Limpopo Province. Curationis 2008;31(1):2837. https://doi.org/10.4102/curationis.v31:1.903

9. Arries E. Practice standards for quality clinical decision-making in nursing. Curationis 2006;29(1):62-72.
10. Mawela K. Changing staff attitude: A key to service delivery. Nursing Update 2014;39(5):1-5.

11. Catallo C, Spalding K, Haghiri-Vijeh R. Nursing professional organisations: What are they doing to engage nurses in health policy? SAGE Open 2014;4(4). https:// doi.org/10.1177/2158244014560534

12. Churchman R, Woodhouse D. Professional, Regulatory \& Statutory Bodies and Higher Education Institutions. New Zealand Universities Academic Audit Unit. AAU Series on Quality No. 1. Wellington: AAU, 1998.

13. Hoskins K, Grady C, Ulrich CM. Ethics education in nursing. Instructions for future generations of nurses. Online J Issues Nursing 2018;23(1).

14. McCarthy CF, Voss J, Salmon ME, et al. Nursing and midwifery regulatory reform in east, central, and southern Africa: A survey of key stakeholders. Hum Resource Health 2013;11(29):1-12. https://doi.org/10.1186/1478-4491-11-29

15. South African Nursing Council. Regulating nursing, advocating for the public. \#Bethatnurse. SANC 2019;(10):1-3.

16. South African Nursing Council. Code of ethics for nursing practitioners in South Africa. Excellence in Professionalism and Advocacy for Healthcare Users. Pretoria: SANC, 2013.

17. South Africa. Nursing Act No. 33 of 2005. Regulations regarding the scope of practice of nurses and midwives.

18. London L, Baldwin-Ragaven L. Human rights and health: Challenges for training nurses in South Africa. Curationis 2008;31(1):5-18. https://doi.org/10.4102/ curationis.v31i1.898.

19. Mogalakwe M. The use of documentary research methods in social research. Afr Sociol Rev 2006;10(1):221-230

20. Bowen GA. Document analysis as a qualitative research method. Qual Res J 2009;9(2):27-40. https://doi.org/10.3316/QRJ0902027.

21. Payne G, Payne J. Key Concepts in Social Research. London: SAGE Publications, 2004.

22. Polit DF, Beck CT. Nursing Research. Generating and Assessing Evidence for Nursing Practice. 9th ed. Philadelphia: Lippincott Williams and Wilkins, 2012.

23. Constitution of the Republic of South Africa. 1996.

24. South African Nursing Council (under the provisions of Nursing Act, 2005). SANC vision and mission statement. Pretoria: SANC, 2004 - 2005.

25. Mabuda T. Legislative framework impacting on nursing education and training Nursing Education Association Conference, Sun City, South Africa, 2012.

26. Styles MM, Schumann MJ, Bickford CJ, et al. Specializing and Credentialing in Nursing Revisited: Understanding the Issues, Advancing the Profession. 1st ed. Silver Spring: American Nurses Association, 2008.

27. South African Nursing Council. Continuous Professional Development Framework for Nurses and Midwives/Accoucheurs in South Africa. SANC circular 3/2018.

28. Er RA, Sehiralti M. Attributes of a good nurse: The opinions of nursing students Nursing Ethics 2017;24(2):238-250. https://doi.org/10.1177\%2F0969733015595543

29. Pera S, van Tonder S. Ethics in Healthcare. 4th ed. Cape Town: Juta, 2018.

30. Stellenberg EL, Dorse AJ. Ethical issues that confront nurses in private hospitals in the Western Cape Metropolitan area. Curationis 2014;37(1):1-9. https://doi. org/10.4102/curationis.v37i1.38

31. Bagnasco A, Catania G, Aleo G, et al. Commentary on nursing ethics article: Facilitating ethics education in nursing students. Nursing ethics 2014;21(6):742743. https://doi.org/10.1177/0969733014538907

32. Antwi A, Chigumba T, Mutambasere A, et al. Social conscience and healthcare professionals: Where does one draw the line? S Afr J Bioethics Law 2013;6(1):6-9. https://doi.org/10.7196/SAJBL.226

33. Armstrong AE. Towards a strong virtue ethics for nursing practice. Nursing Philosophy 2006;7(3):110-124. https://doi.org/10.1111/j.1466-769X.2006.00268.X

34. De Vries R, Gordijn B. Empirical ethics and its alleged meta-ethical fallacies. Bioethics 2009;23(4):193-201. https://doi.org/10.1111/j.1467-8519.2009.01710.x

Accepted 7 April 2020 